\title{
Anesthetic management of the first pediatric bilateral hand transplant
}

\section{Prise en charge anesthésique de la première greffe bilatérale des mains chez un enfant}

\author{
Harshad G. Gurnaney, MBBS, MPH • John E. Fiadjoe, MD - L. Scott Levin, MD • \\ Benjamin Chang, MD · Heather Delvalle, MD · Jorge Gálvez, MD $\cdot$ Mohamed A. Rehman, MD
}

Received: 1 December 2015/Revised: 3 February 2016/Accepted: 25 February 2016/Published online: 7 March 2016

(C) Canadian Anesthesiologists' Society 2016

\begin{abstract}
Purpose The purpose of this case report is to describe the anesthetic and case management of the first vascularized composite allograft pediatric bilateral hand transplant.

Clinical details Our patient was an eight-year-old male with a medical history of Staphylococcus aureus sepsis at one year of age that resulted in end-stage renal disease as well as bilateral upper and lower extremity amputations. After referral for bilateral hand transplantation, the transplantation team, with expertise in all aspects of perioperative care (surgery, anesthesiology, nephrology, renal transplantation, pediatric intensive care, and therapeutic pharmacy), was consulted to help develop anesthetic and other perioperative protocols for surgery. Prior to activation of the transplantation team, the lead surgeon evaluated potential donors by comparing a threedimensional printed model of the recipient's forearm with the donor's upper extremities to ensure an adequate match. The anesthesia team inserted bilateral ultrasound-guided infraclavicular catheters to provide a sympathetic block to
\end{abstract}

H. G. Gurnaney, MBBS, MPH (ه) - J. E. Fiadjoe, MD .

H. Delvalle, MD · J. Gálvez, MD · M. A. Rehman, MD

Department of Anesthesiology and Critical Care Medicine, The

Children's Hospital of Philadelphia, Perelman School of

Medicine at University of Pennsylvania, Philadelphia, PA, USA

e-mail: gurnaney@email.chop.edu

L. S. Levin, MD

Department of Orthopaedic Surgery, Perelman School of

Medicine at University of Pennsylvania, Philadelphia, PA, USA

B. Chang, MD

Department of Plastic and Reconstructive Surgery, Perelman

School of Medicine at University of Pennsylvania, Philadelphia,

PA, USA facilitate blood flow to the upper extremities and to provide both intraoperative and postoperative pain control. The patient remained in the operating room for $13 \mathrm{hr} 37 \mathrm{~min}$ for a surgical time of ten hours $39 \mathrm{~min}$. He remained in the hospital for 34 days after the procedure and was then transferred to an inpatient rehabilitation facility for a further 15 days. The patient is currently doing well in a postoperative rehabilitation program. He has demonstrated motor power to the hands using the forearm muscles but is not expected to reach his maximum sensory function for at least one to two years.

Conclusion This report describes the anesthetic management of the first pediatric bilateral hand transplant. This procedure required considerable preoperative planning and communication between various teams to ensure all resources needed to deliver the care for this complex and novel transplant surgery were readily available.

\section{Résumé}

Objectif L'objectif de cette présentation de cas est de décrire la prise en charge anesthésique et la gestion du cas de la première greffe bilatérale des mains chez un enfant à partir d'une allogreffe de tissu composite.

Détails cliniques Notre patient était un garçon de huit ans présentant des antécédents médicaux de sepsis dû à un staphylocoque doré contracté à l'âge d'un an, qui a entraîné une insuffisance rénale terminale ainsi que l'amputation bilatérale des membres supérieurs et inférieurs. Après son aiguillage pour une greffe bilatérale des mains, l'équipe de transplantation, forte d'une vaste expertise en soins périopératoires (chirurgie, anesthésiologie, néphrologie, transplantation rénale, soins intensifs pédiatriques et pharmacie thérapeutique), a été consultée afin de mettre au point des protocoles 
anesthésiques et périopératoires pour la chirurgie. Avant de réunir l'équipe de transplantation, le chirurgien responsable a évalué les donneurs potentiels en comparant un modèle imprimé en trois dimensions de l'avant-bras du récipiendaire aux membres supérieurs du donneur afin de garantir une bonne correspondance. L'équipe anesthésique a inséré des sondes infraclaviculaires bilatérales par échoguidage afin de réaliser un bloc sympathique qui faciliterait l'apport sanguin aux membres supérieurs et contrôlerait la douleur pendant et après l'opération. Le patient est resté en salle d'opération pendant $13 \mathrm{~h} 37 \mathrm{~min}$, et la chirurgie a duré $10 \mathrm{~h} 39 \mathrm{~min}$. Il est resté à l'hôpital 34 jours après l'intervention, puis a été transféré à un centre de réadaptation pour patients hospitalisés pour 15 jours supplémentaires. Le patient se porte actuellement bien et participe à un programme de réadaptation postopératoire. Il a démontré un pouvoir moteur aux mains en utilisant les muscles des avant-bras, mais on ne s'attend pas à ce qu'il atteigne sa fonction sensorielle maximale avant au moins un ou deux ans.

Conclusion Ce compte rendu décrit la prise en charge anesthésique de la première greffe bilatérale des mains chez un enfant. Cette intervention a nécessité une planification et une communication préopératoires importantes entre diverses équipes afin de s'assurer que toutes les ressources nécessaires à prodiguer les soins optimaux pour cette chirurgie de greffe complexe et innovante soient immédiatement disponibles.

In 1998, the first successful hand transplant was performed, heralding the modern era of the clinical vascularized composite allograft (VCA). ${ }^{1}$ Unlike solid organs, VCAs are composed of multiple tissues, including skin, muscle, tendons, vessels, nerves, lymph nodes, bone, and bone marrow. Today, VCAs are increasingly being performed. $^{2-4}$ Herein, we outline the perioperative planning and anesthetic management of the first pediatric bilateral hand transplant.

\section{Clinical case}

An eight-year-old male (18.1 $\mathrm{kg})$ presented for consideration for bilateral hand VCA transplant. The patient had a medical history of severe Staphylococcus aureus sepsis at one year of age, resulting in both end-stage renal disease and bilateral upper forearm and lower limb below the knee amputations. He had received a livingrelated kidney transplant at age five years and was maintained on mycophenolate and tacrolimus for post-

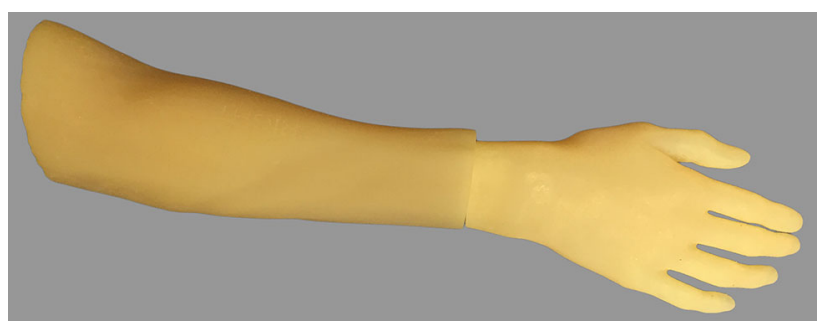

Fig. 1 Three-dimensional printed anatomic model of the recipient's forearm for donor matching

renal transplant immunosuppression. At the time of his present procedure, he had excellent renal function (serum creatinine, $44.2 \mu \mathrm{mol} \cdot \mathrm{L}^{-1}$ ). A right subclavian port-acatheter was in situ for long-term central venous access and had been placed three years prior to his hand transplant procedure.

The patient's preoperative planning included multiple transplantation team meetings prior to his registration with the United Network for Organ Sharing list for a VCA transplant. These meetings were held to develop care protocols and to reach consensus on immunosuppressive management, and involved input from the anesthesiology, nephrology, renal transplant, pediatric intensive care, and therapeutic pharmacy teams. The transplantation team additionally developed a perioperative antibiotic and antiviral prophylaxis plan and a plan for post-transplant anticoagulation. A preoperative ultrasound evaluation was performed to assess the patient's venous system and to document patency of the bilateral subclavian, internal jugular (IJ), and femoral veins, as these were potential locations for perioperative central venous cannulation. A preoperative echocardiogram showed normal biventricular function and the electrocardiogram was also normal.

The 30-member operating room transplantation team consisted of surgeons, nursing staff, nurse practitioners, and anesthesiologists. A three-dimensional (3D) printed anatomic model of the recipient's forearm had been generated in order to assess the donor hands adequately and to approximate the desired hand size for the recipient (Fig. 1). ${ }^{5}$ The lead surgeon activated the team after visually inspecting the donor hands and comparing the printed 3D model with the donor's upper extremities.

On the day of surgery, the availability of blood products (four units of packed red blood cells [PRBCs] and four units of fresh frozen plasma) was confirmed with the blood bank, and arrangements were made to cross-match additional units after two units had been administered. The patient was brought to the operating room after fasting overnight, and intravenous midazolam $(2 \mathrm{mg})$ was given to facilitate parental separation. Anesthesia was induced with fentanyl $(50 \mu \mathrm{g})$, propofol $(50 \mathrm{mg})$, and rocuronium (40 
mg) through his previously implanted single-lumen indwelling subclavian port-a-catheter, and his trachea was intubated with a 5.5-mm oral endotracheal tube. Additional central venous access was obtained with a 5 -French $12-\mathrm{cm}$ triple-lumen catheter placed under ultrasound guidance in his left IJ vein. A 2.5 -French 5 -cm catheter was inserted into his left femoral artery. Monitoring of his central venous and arterial pressure continued throughout the surgery and in the postoperative period. Anesthesia was maintained with isoflurane and intermittent boluses of rocuronium (10-20 mg). He received one additional dose of fentanyl $(25 \mu \mathrm{g})$.

Following placement of the invasive hemodynamic monitors, bilateral ultrasound-guided infraclavicular catheters were inserted in order to provide sympathetic block to facilitate upper extremity blood flow and to provide both intraoperative and postoperative pain control. The catheters were positioned near the posterior cord of the brachial plexus as local anesthetic infused through a catheter near the posterior cord has been shown to spread to the medial and lateral cords. ${ }^{6}$ Both catheters were secured with a dressing at the site of catheter entry. The right infraclavicular catheter was placed laterally to the coracoid process to avoid interference with the catheter of the single-lumen port that was visualized throughout the procedure using ultrasound guidance. A bolus of $0.2 \%$ ropivacaine $9 \mathrm{~mL}$ was given through each infraclavicular catheter immediately after they were placed, and ultrasound guidance was used to confirm the spread of local anesthetic in the region of the posterior cord. At the end of the case, a further bolus of $0.2 \%$ ropivacaine $4 \mathrm{~mL}$ was administered through each infraclavicular catheter along with a continuous infusion of $0.13 \%$ ropivacaine at 4 $\mathrm{mL} \cdot \mathrm{hr}^{-1}$ initiated using an Elastomeric ON-Q ${ }^{\circledR}$ pump (IFlow Corporation, VQ OrthoCare, Irvine, CA, USA) through each infraclavicular catheter.

A warm ambient temperature was maintained in the operating room throughout the procedure and prior to the start of surgery. A Bair-Hugger ${ }^{\circledR}$ forced-air warmer (Arizant Healthcare, Inc., Eden Prairie, MN, USA) was applied to the patient's chest and lower body, and all intravenous fluids and blood products were administered through fluid warmers. The patient's body temperature was maintained at $\geq 37^{\circ} \mathrm{C}$ at the time of reperfusion of his hands. The patient was placed in the supine position and both upper extremities were prepped into the surgical fields in a sterile fashion. The surgical drapes covered the entire patient leaving limited access to the patient's head under the surgical drapes.

Prior to surgical incision, methylprednisolone sodium succinate $275 \mathrm{mg}\left(15 \mathrm{mg} \cdot \mathrm{kg}^{-1}\right)$ and cefazolin $575 \mathrm{mg} \mathrm{(30}$ $\mathrm{mg} \cdot \mathrm{kg}^{-1}$ ) were administered, and an infusion of antithymocyte globulin $1.5 \mathrm{mg} \cdot \mathrm{kg}^{-1}$ (with a 0.22 micron filter for administration) was given over six hours. The initial dissection phase of the recipient's forearms involved tagging the blood vessels, nerves, and tendons. This was facilitated with bilateral upper extremity pneumatic tourniquets to $200 \mathrm{mmHg}$. The donor hands were preserved with University of Wisconsin solution and maintained at $4^{\circ} \mathrm{C}$ after procurement for transportation. The hands were warmed to a temperature of $20^{\circ} \mathrm{C}$ prior to transplantation. The ischemic time was $208 \mathrm{~min}$ for each hand, with four surgical teams working simultaneously to minimize the preparation/ischemic time of the donor hands. Once the recipient's arms and donor hands had been prepared, the bony fixation was performed followed by arterial anastomosis. The hands were flushed with University of Wisconsin solution prior to reperfusion. The tourniquets were inflated on the left arm for $100 \mathrm{~min}$ and on the right arm for 115 min during the dissection of the recipient forearms. The clamps were removed after the arterial anastomosis, and the patient continued to bleed from the surgical site requiring frequent PRBC transfusions. Intravenous heparin (50 units $\left.\cdot \mathrm{kg}^{-1}\right)$ was administered after the arterial anastomosis just prior to reperfusion of the hand. The bleeding decreased following completion of the venous anastomosis but continued until completion of the procedure. We increased replacement of blood products because of hypotension-mean arterial pressure (MAP) decreased from $65-70 \mathrm{mmHg}$ to $50-60$ $\mathrm{mmHg}$ for about ten minutes-after the arterial anastomosis and initiated low-dose dopamine (2-5 $\mu \mathrm{g} \cdot \mathrm{kg}^{-1} \cdot \min ^{-1}$ ) for about $60 \mathrm{~min}$ during this phase to help maintain MAP $>65 \mathrm{mmHg}$. The hemoglobin $(\mathrm{Hb})$, platelet count, prothrombin time, activated partial thromboplastin time, and international normalized ratio
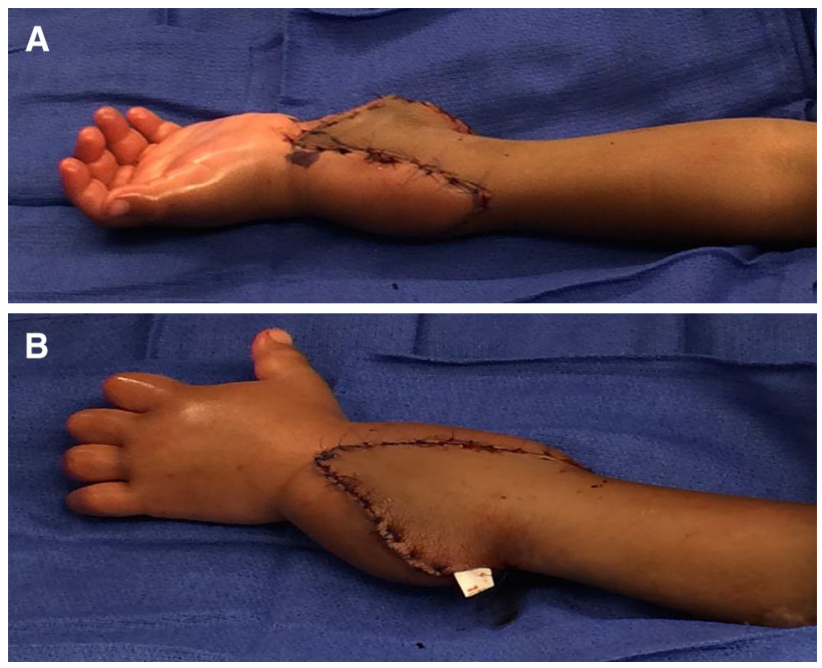

Fig. 2 The volar (A) and dorsal (B) aspects of the left hand and forearm are shown with the anastomosis between the donor hand and recipient forearm clearly visible 
were measured every two hours for the duration of the surgery. The central venous pressure was maintained at approximately 6-7 $\mathrm{mmHg}$ after the arterial anastomosis. Other than the one ten-minute episode of MAP $<60$ $\mathrm{mmHg}$, the patient's overall MAP stayed at $65-75 \mathrm{mmHg}$ for the majority of the case with only transient decreases to $60 \mathrm{mmHg}$ that were treated with fluid resuscitation. Intraoperatively, the patient received $1,204 \mathrm{~mL}$ of PRBCs, $750 \mathrm{~mL}$ of albumin, $300 \mathrm{~mL}$ of plasma, and $2,450 \mathrm{~mL}$ of lactated Ringer's solution. Administration of PRBCs was initiated prior to release of the arterial clamp in order to target $\mathrm{Hb}>100 \mathrm{~g} \cdot \mathrm{L}^{-1}$. The $\mathrm{Hb}$ range throughout the procedure was $93-123 \mathrm{~g} \cdot \mathrm{L}^{-1}$, and the urine output was $1,800 \mathrm{~mL}$ for the $12 \mathrm{hr}$ of surgery.

At the completion of surgery, the patient was sedated with intermittent propofol boluses and transported to the pediatric intensive care unit (PICU) for supportive care and neurovascular monitoring of the newly transplanted hands (Fig. 2). Within two hours of his arrival to the PICU, his right hand appeared pale and the Doppler assessment showed an absent pulse. As a result, a bolus dose of heparin (100 units. $\mathrm{kg}^{-1}$ ) was administered, and the hand transplant and anesthesia teams were notified of the need for reoperation. The patient was immediately transported back to the operating room for an exploration of the right hand.

The right hand exploration revealed that the ulnar artery was kinked, and therefore, both the arterial and venous anastomoses on the right hand were revised with immediate return of perfusion to the hand. The patient was given an additional unit of PRBCs during the reexploration and then brought back to the PICU and started on a heparin infusion (titrated to a partial thromboplastin time of 60-85 sec) to prevent thrombosis in his transplanted hands after the re-exploration. On postoperative day (POD) 3 , the heparin infusion was replaced with twice daily enoxaparin $(18 \mathrm{mg})$ titrated to an anti-Xa activity of 0.5-1 units $\cdot \mathrm{mL}^{-1}$ and acetylsalicylic acid $\left(81 \mathrm{mg} \cdot \mathrm{day}^{-1}\right)$. His trachea was extubated on POD 2 and his pain was well controlled using the bilateral infraclavicular catheters. On POD 4, his MAP targets were decreased from 65 to 55 $\mathrm{mmHg}$ secondary to increasing peripheral edema from multiple fluid bolus administration. His $\mathrm{Hb}$ was maintained at approximately $100 \mathrm{~g} \cdot \mathrm{L}^{-1}$ throughout the postoperative period. We continued his infraclavicular catheter infusions until POD 8, at which point his pain was well controlled with oral pain medications.

After transplantation, he was continued on intravenous Thymoglobulin $\left(1.5 \mathrm{mg} \cdot \mathrm{kg}^{-1} \cdot \mathrm{day}^{-1}\right)$ for three days. In addition, his intravenous methylprednisolone was transitioned to oral prednisolone that was slowly tapered over three months to $0.2 \mathrm{mg} \cdot \mathrm{kg}^{-1} \cdot \mathrm{day}^{-1}$. He was restarted on his preoperative tacrolimus with a targeted level of 8-12 $\mathrm{ng} \cdot \mathrm{mL}^{-1}$, and his mycophenolate dose increased to $400 \mathrm{mg}$ $q 12 \mathrm{hr}$ postoperatively. Cefazolin was continued postoperatively for antibiotic prophylaxis, and daily cotrimoxazole (trimethoprim/sulfamethoxazole) was administered for one year. Antiviral prophylaxis was also given, including intravenous ganciclovir, which was transitioned to oral valganciclovir and continued for six months.

Our patient was transferred to an inpatient rehabilitation centre on POD 49. He is currently doing well, has recovered some motor function in his hand (related to his forearm muscles), and is expected to recover sensory function in his hand progressively over the next one to two years. He continues to have regular follow-up with the hand transplant team to monitor his progress and watch for any signs of rejection.

\section{Discussion}

This case report describes the perioperative management of the first pediatric bilateral hand transplant patient. The anesthesia team was involved in planning for this case for about two years prior to the actual hand transplantation. We reviewed the adult literature on hand transplants and incorporated the findings of our review into our practice guidelines. ${ }^{7,8}$ Our goals in this case were to assist the surgical team in selecting the appropriate donor; achieve adequate access (venous and arterial) for intraoperative and postoperative management of the patient's hemodynamic parameters; optimize blood flow to the graft using a regional anesthetic technique (infraclavicular catheters), and maintain adequate renal function and perfusion throughout the case. ${ }^{7}$

Fluid management during hand transplantation can be challenging as it is difficult to measure blood loss accurately because of the large amount of irrigation solution (especially prior to reperfusion) and ice slushes used for organ preservation. There is significant blood loss when the tourniquets are released after the arterial anastomosis, and blood loss continues until completion of the venous anastomosis. The patient's MAP was maintained at $>65 \mathrm{mmHg}$ to provide optimal flow to the hands. Maintaining intravascular volume during this period is crucial as alpha-adrenergic agonists (epinephrine, phenylephrine) may increase the risk of vasoconstriction in the transplanted hands.

Consideration should be given to planning for blood transfusion, keeping in mind that dealing with overtransfusion is as critical as treating anemia. ${ }^{8}$ Particular consideration should be directed towards hyperkalemia and hypocalcemia which can result from large-volume blood transfusions. ${ }^{9}$ Vigilance is needed to 
detect early signs of hyperkalemia (peak $\mathrm{T}$ waves, shortened QT interval, ST depression etc.). Furthermore, some blood preparation strategies, such as irradiation to reduce the risk of graft $v s$ host reaction, may increase the risk of hyperkalemia. To counteract this occurrence, washing PRBCs is encouraged. ${ }^{10}$ It is important to balance the need for improved oxygen delivery with increased viscosity secondary to higher hematocrit that could lead to a compromise in perfusion to the transplanted organ. ${ }^{11}$ Optimizing hand blood flow requires maintenance of normothermia during the procedure as hypothermiaassociated vasoconstriction could reduce the blood supply to the graft. $^{8}$

During the planning period, we emphasized using regional anesthesia to provide postoperative pain control as well as to help improve perfusion to the new graft by causing a sympathectomy. ${ }^{12}$ Studies in adults suggest that a sympathectomy from a peripheral nerve block can improve perfusion to the affected limb. ${ }^{13}$ The rationale for selecting an infraclavicular location to place a brachial plexus block in this patient was to avoid the more mobile cervical region in a child where a central venous catheter had already been placed. In addition, the risk of phrenic nerve paresis with the infraclavicular block is lower than with a supraclavicular block. As we were performing bilateral blocks, it was important to avoid phrenic nerve paresis to facilitate postoperative tracheal extubation. ${ }^{14,15}$ In our view, this location provides a more stable location for a long-term (seven to ten days postoperatively) catheter with less risk of being dislodged. ${ }^{16}$ The patient did complain of pain on the lateral aspect of his right forearm on POD 5 (in the region of the musculocutaneous nerve). This might have been associated with placing the right infraclavicular catheter at a lateral location secondary to the right-sided subclavian port catheter, which resulted in insufficient distribution of the local anesthetic infusion to the musculocutaneous nerve on the right side. The patient reported good pain control after receiving a $3-\mathrm{mL}$ bolus of $0.2 \%$ ropivacaine through the right infraclavicular catheter.

Vascular access posed a particular challenge for our patient. Peripheral vascular access is limited by the nature of the operation as well as by the history of bilateral lower extremity amputations. ${ }^{17}$ Prior to the transplantation date, he had undergone insertion of a single-lumen port for longterm vascular access. In addition to this, we planned to insert an IJ central venous catheter for venous access during the procedure as well as for the immediate postoperative care in the PICU. The post-transplantation course demands routine phlebotomy to guide immunosuppressive therapy and for additional procedures requiring general anesthesia. When possible, central access, such as ports, should be used if available.
Nevertheless, if central access routes are unavailable, the anesthesiologists should discuss the individual situation with the transplantation team to ensure an appropriate site is chosen for peripheral vascular access while minimizing risk to the VCAs. In our discussion with the transplant surgeons, they expressed comfort with phlebotomy in the VCAs about six months after the procedure, but they asked that tourniquet placement be avoided or used for the shortest time possible.

Psychological preparation of a child for a hand transplant is critical to the long-term success of the transplantation. Preoperatively, our patient was evaluated by a team of psychologists and social workers to assess his emotional maturity and intellectual capacity for understanding and accepting the physical change resulting from hand transplantation. This also helped the team develop a strong relationship with the patient prior to his transplant surgery. He also met with the hand rehabilitation team to assess his intellectual and emotional maturity and to determine his ability to engage actively in hand rehabilitation after the surgery. The months of full-time rehabilitation required after hand transplantation present specific challenges in children, particularly the physiotherapy which can encroach on the time available for primary education.

\section{Conclusion}

We report on the detailed anesthetic management of the first pediatric bilateral hand transplant operation with particular emphasis on achieving adequate vascular access, maintaining adequate hemodynamics and temperature to optimize blood flow to the graft, using regional anesthesia for perioperative sympathectomy and pain control, and maintaining adequate renal perfusion throughout the procedure. This procedure required considerable preoperative planning and communication between various teams to ensure all resources needed to deliver the care for this complex and novel transplant surgery were readily available.

Author contributions: Harshad G. Gurnaney, Scott L. Levine, Benjamin Chang, Jorge Galvez, John E. Fiadjoe, Mohammed Rehman, and Heather Delvalle contributed substantially to the conception and design of the manuscript. Harshad G. Gurnaney, Scott L. Levine, Benjamin Chang, and Jorge Galvez contributed substantially to the acquisition of data. Harshad G. Gurnaney, John E. Fiadjoe, Mohammed Rehman, Scott L. Levine, Benjamin Chang, and Jorge Galvez contributed substantially to drafting the article.

Acknowledgements We sincerely acknowledge all the perioperative and clinical staff at Children's Hospital of Philadelphia who were involved in the planning and clinical care of this challenging case. We also gratefully acknowledge Christine 
McAndrew, Todd J Levy, and Deborah Humpl who helped in the clinical care and manuscript preparation.

Source(s) of support Departmental funds.

Conflicts of interest None declared.

\section{References}

1. Jones JW, Gruber SA, Barker JH, Breidenbach WC. Successful hand transplantation. One-year follow-up. Louisville Hand Transplant Team. N Engl J Med 2000; 343: 468-73.

2. Amirlak B, Gonzalez R, Gorantla V, Breidenbach WC 3rd, Tobin GR. Creating a hand transplant program. Clin Plast Surg 2007; 34: 279-89.

3. Botvin JD. Pioneering hand transplant surgery at Jewish Hospital, Louisville. Transplant team uses hands-on approach with media. Profiles Healthc Mark 2001; 17: 18-26.

4. Kaufman $C L$, Breidenbach W. World experience after more than a decade of clinical hand transplantation: update from the Louisville hand transplant program. Hand Clin 2011; 27: 417-21, vii-viii.

5. Galvez JA, Gralewski K, McAndrew C, Rehman MA, Chang B, Levin $L S$. Assessment and planning for a pediatric bilateral hand transplant using 3-dimensional modeling: case report. J Hand Surg Am 2016. DOI: 10.1016/j.jhsa.2015.12.010.

6. Ponde V, Shah D, Johari A. Confirmation of local anesthetic distribution by radio-opaque contrast spread after ultrasound guided infraclavicular catheters placed along the posterior cord in children: a prospective analysis. Paediatr Anaesth 2015; 25: 2537.

7. Elkassabany NM, Fosnot CD, Shaked A, et al. Perioperative management of a patient scheduled for bilateral hand transplant. J Clin Anesth 2013; 25: 224-7.
8. Lang RS, Gorantla VS, Esper S, et al. Anesthetic management in upper extremity transplantation: the Pittsburgh experience. Anesth Analg 2012; 115: 678-88.

9. Lee AC, Reduque LL, Luban NL, Ness PM, Anton B, Heitmiller ES. Transfusion-associated hyperkalemic cardiac arrest in pediatric patients receiving massive transfusion. Transfusion 2014; 54: 244-54.

10. Swindell CG, Barker TA, McGuirk SP, et al. Washing of irradiated red blood cells prevents hyperkalemia during cardiopulmonary bypass in neonates and infants undergoing surgery for complex congenital heart disease. Eur J Cardiothorac Surg 2007; 31: 659-64.

11. Sigurdsson GH, Thomson D. Anaesthesia and microvascular surgery: clinical practice and research. Eur J Anaesthesiol 1995; 12: 101-22.

12. Li J, Karmakar MK, Li X, Kwok WH, Ngan Kee WD. Regional hemodynamic changes after an axillary brachial plexus block: a pulsed-wave Doppler ultrasound study. Reg Anesth Pain Med 2012; 37: 111-8.

13. Sahin L, Gul R, Mizrak A, et al. Ultrasound-guided infraclavicular brachial plexus block enhances postoperative blood flow in arteriovenous fistulas. J Vasc Surg 2011; 54: 749-53.

14. Chin KJ, Alakkad H, Adhikary SD, Singh M. Infraclavicular brachial plexus block for regional anaesthesia of the lower arm. Cochrane Database Syst Rev 2013; 8: CD005487.

15. Perlas A, Lobo $G$, Lo $N$, Brull R, Chan VW, Karkhanis $R$. Ultrasound-guided supraclavicular block: outcome of 510 consecutive cases. Reg Anesth Pain Med 2009; 34: 171-6.

16. Gurnaney H, Kraemer FW, Maxwell L, Muhly WT, Schleelein L, Ganesh A. Ambulatory continuous peripheral nerve blocks in children and adolescents: a longitudinal 8-year single center study. Anesth Analg 2014; 118: 621-7.

17. Rinat C, Ben-Shalom E, Becker-Cohen R, Feinstein S, Frishberg $Y$. Complications of central venous stenosis due to permanent central venous catheters in children on hemodialysis. Pediatr Nephrol 2014; 29: 2235-9. 